\title{
A Survey on Cognitive Radio Network using Artificial Neural Network
}

\author{
Adnan Waqar ${ }^{1}$, Saima Khadim ${ }^{1}$, Aamir Zeb ${ }^{2}$, Samreen Amir ${ }^{1}$ and Imran Khan ${ }^{1}$ \\ ${ }^{1}$ Dawood University of Engineering and Technology, Karachi, Pakistan \\ ${ }^{2}$ NED University of Engineering and Technology, Karachi, Pakistan
}

\begin{abstract}
The emergence of Internet of Things and other applications of wireless communication has resulted in increase of air interference among various wireless devices. In upcoming time we will be connecting more and more devices wirelessly. In addition to an increase in number of devices, many devices also demand higher bandwidth. We have a limited spectrum available for communication and as the demand increases it creates more and more congestion in the available spectrum. Besides this scarcity of spectrum, it has been observed that all available frequencies in this spectrum are not efficiently utilized. Some frequency bands face congestion while others are underutilized. The solution of all these issues is Cognitive Radio. The fundamental theory of cognitive radio deals with the issues mentioned above and provides efficient utilization of available spectrum. In cognitive radio when a frequency is not utilized by primary user (Licensed user), it is allocated to secondary user (Unlicensed user) who can use the frequency until there is no primary user. For searching primary and secondary user we use spectrum sensing. Depending on the type of users and the environment, this spectrum sensing can be a time consuming task which can severely impact the QoS. To deal with this critical issue we use machine learning techniques, which predict spectrum holes in an available frequency band. This in turn reduces spectrum sensing time and power consumed in sensing. Among various Machine learning techniques, Artificial Neural Networks is one of the most popular and widely used technique. Unlike other Machine learning Techniques, Neural Network doesn't require prior knowledge of the system and in most cases it doesn't require the model to be retrained an every instance. These advantages makes it one of the most popular technique for cognitive radios. So far a lot of work has been done on implementing Artificial Neural Network models for predicting the most suitable frequency for a secondary user. In this paper a comprehensive survey has been conducted on various ANN techniques, its comparison with other machine learning techniques and discussion on various learning models to increase the decision making ability of cognitive radio's cognitive engine. ANN uses supervised learning and this paper compares it with other supervised learning techniques (like SVM) and also unsupervised learning techniques and statistical models. The paper provides detailed knowledge about what factors influence the use of ANN in cognitive engines and under certain conditions which ANN technique is most suitable.
\end{abstract}

Keywords: Cognitive Radio Network, Spectrum Prediction, Artificial Neural Network, Machine Learning

\section{Introduction}

As the spectrum scarcity has increased, Dynamic spectrum access (DSA) is considered to be a vital element of future communication. Spectrum can be divided into three categories, black spaces, white spaces and grey spaces [1]. Unlike Static spectrum access,

Received (May 2, 2017), Review Result (August 30, 2017), Accepted (September 8, 2017) 
DSA can considerably solve the issue of imbalance in spectrum utilization. Cognitive radio defines the use for both licensed and unlicensed users for dynamically accessing the spectrum. CR makes decision by sensing both the outer environment and internal parameters [2]. The FCC defines high throughput, minimum interference and interoperability as operating parameters of $\mathrm{CR}$ [3] .Recently we have seen the standardization of first air interference standard, the IEEE 802.11 standard utilizing Television white spaces (TVWS) for wireless regional area networks (WRANs). As the need for higher bandwidth will increase and simultaneously number of wireless devices rise, importance of cognitive radio will also increase. CR has the ability to improve capacity [4] and spectrum access [5]. The Cognition i.e learning and reasoning ability of cognitive radio is provided through a number of ways. But one of the most popular way of providing this cognition is implementing machine learning techniques. CR can be used in various applications like spectrum markets [6], grid communications [7], Public safety [8], femtocells [9], self-organizing networks [10]. These machine learning techniques enables the cognitive engine to make accurate decisions, saving time and power and making the system more reliable. In this paper we will focus on artificial neural networks (ANN), one of the most widely used machine learning technique for cognitive radio. We will discuss how ANN supports cognitive radio, its comparison with other machine learning techniques and several models proposed by various authors that improves the performance of ANN.

\section{Artificial Neural Networks (ANN)}

ANN are computational tools inspired by Brain's working of neurons. The idea was first presented by the neurophysiologist W. McCulloch and the logician W. Pits in 1943. ANN are provided with input and output data, than they are trained mapping input to the target output [11]. The neurons are arranged in three layers, input layer, output layer and the hidden layer. Artificial neuron gets input from all neighbouring neurons and then adjusts itself depending on synaptic weight and activation function. Each neuron produces its single output value by accumulating inputs from other neurons. Learning of ANN is achieved till the difference between the required output and output of network is negligible. ANN is a nonlinear function with flexible parameters to give required output [12]. ANN has the ability to learn different patterns, features and attributes. By learning the neurons' output are systematically adjusted and they can give result for new conditions or datasets. ANN has been used in spectrum sensing for CR [13, 14]. [15] has used ANN to categorize different IEEE 802.11 signals. [14] used ANN in spectrum sensing algorithm for wireless mesh networks. In CRs for radio parameters adaption, ANN is used in $[16,17]$. Having different training methods and configuration types, we have different types of ANN. In this paper we will limit our scope to the types of ANNs used with cognitive radio.

1) MLPN: Multi-layer linear perceptron networks (MLPNs) It consists of layers of neurons connected to previous layer's output in linear combination. The weights are randomly chosen and then adjusted to give accurate results. For adjusting the weights, methods like genetic algorithm (GA) or back propagation (BP) [12] can be used.

2) NPN: By introducing nonlinearity in the network we can make the network adapt the sample set. This can be achieved by cross-multiplying two inputs or squaring inputs. However, for training weights BP can make the network slow by increasing processing time.

3) RBFN: Perceptron networks have the problem of settling into local minimals. This problem is resolved in RBFN which has a distance criterion w.r.t centre in its hidden layer. It's a radial nonlinear function which can be Gaussian, Euclidean or any other. For training gradient descent method is used. 


\section{Cognitive Radio and ANN}

Studies have shown that certain parts of spectrum are over utilized while others are underutilized. [18]. When primary user doesn't uses a band of frequencies in certain region or time period, it creates a Spectrum hole and cognitive radio exploits this availability by using it as secondary (unlicensed) user. [18] Self programming is one of the key aspect of Cognitive radio [19][20]. In [21] Haykin defines that two main objectives of CR are efficient utilization of spectrum and ensuring reliable communication. [22]. [23]-[24], defines a cognitive engine with its cognitive core performing all the learning and reasoning task. CR should be equipped with learning and reasoning ability [25], [20], [26], [27]. This learning and reasoning requires AI techniques. Various AI techniques include, neural network, fuzzy logic, hidden markov model and genetic algorithm [28, 29]. Through CRs techniques of dynamic spectrum sharing (DSS) are developed for efficiently using crowded frequency bands. [21, 30, 31, 32] In recent years research has been done on applying machine learning techniques on CRs [33], [34].

\section{Machine Learning models/techniques proposed for Implementation on Cognitive Radio}

In [35] the purpose is to utilize the unused spectrum (i.e tv white spaces, UHF \& VHF band) which is not currently used by the primary user without causing interference to the primary user. To minimize the interference to the PU, SU need a reliable sensing techniques which sense the whole spectrum. Spectrum sensing is an important function for the secondary user to determine the availability of channel, however spectrum sensing consumes larger amount of energy which can be mitigated by using predictive method. Spectrum prediction is achieved by using neural network multilayer perceptron (MLP) which improves the spectrum utilization and also reduces the sensing energy. [36] provides longest idle time of unused spectrum to the unlicensed user by using machine learning technique. Four supervised machine learning techniques (two from ANN and two from SVM) are used to investigate the prediction of length of the off period of the primary user. Poisson, Interrupted Poisson and Self similar models are used for the traffic prediction

In paper [37], predicts the idle slots in the channel which is based on the past information and then allow CR to select best slot for data transmission. For idle slots prediction, Neural Network Levenberg-Marquardt (NNLM) algorithm is used. The authors find that NNLM algorithm gives fast and accurate prediction as compare to MLP and HMM. In [38] the goal is to maximize or increase the decision accuracy in the presence of noise in the environment for secondary user by using neural network based spectrum sensing. Neural network is an intelligent or smart technique to predict the unused spectrum with the capabilities to understand the environment, adjust and learn in real time operating parameters as per requirement of Cognitive user's.

In this paper [39 ] the basic purpose is to increase decision accuracy under various noisy condition and it is implemented by using Multilayer Perceptron. Neural Network that intensify or upgrade the required throughput and the performance is figure out by using three types of Neural Network through Simulation which are Perceptron Neural Network, Feed forward Neural Network and Elman Neural Network. From the Simulation results it is observed that performance of Perceptron Neural Network is better than Feed Forward Neural Network and Elman Neural Network.

In [40] Contextual sigma-if neural network is used to predict the status of channel or spectrum status for Cognitive Radio. From the simulation results it is concluded that the Contextual Sigma-if algorithm sensing time for prediction. [41] compared the performance of two most popular neural network algorithms, Multilayer Perceptron Neural Network and Radial Basis Function Neural Network. The mean square error value 
of MLP is 0.066666 and mean square error value of RBF is 0.0835026 so from the simulation results it is concluded that the Multilayer Perceptron is slightly better than Radial Basis Function.

In this paper, the author used the Combination of Cognitive Radio and Back Propagation (BP) Artificial Neural Network (ANN) both together for the replacement of Complicated Frequency allocation, from the Simulation author comparing Back Propagation (BP) Artificial Neural Network (ANN) with the original Frequency Allocation which is able to give out the accurate simulation results which means that the BP ANN gave the solution of Complicated frequency allocation and by using this method we will get accurate results of frequency allocation which also increases the Quality of Service and reduces the interference[42].

In [43], the author discussed the different work with the combination of Cognitive Radio and Artificial Neural Network for the prediction of Spectrum and then predicted spectrum assigned to the Cognitive user without causing any interference, reduces sensing time of entire band again and again and also increases Quality of Service (QoS). Further author suggested that the Cognitive Radio can be applied in different areas like disaster management and aeronautical air ground interference. In aeronautical air ground spectrum allocation is fixed which are allocated to the aircraft while Cognitive Radio is as a promising solution of fixed spectrum allocation

In this paper, the author used Artificial Neural Network (ANN) model for the prediction of the Spectrum holes. The ANN model predicts the channel capacity, channel capacity is an important parameter to determine channel status whether it is occupied or not. The spectrum sensing has the capability of Cognitive Radio which sense the unused spectrum which is not currently used by the Primary users and then allot to the Unlicensed user. Also, author designed three ANN models with different hidden layers and having multiple neurons. From the Simulation results it is observed that the results of ANN model 3 are more accurate than the ANN model 1 and ANN model 2 [44]

In [45], the author used Improved-Back-Propagation Neural Network for the Prediction of unused Spectrum to mitigate the problems which occurred by using the Conventional Back-Propagation Neural Network. The Back-Propagation Neural Network enhanced by the gradient momentum descent algorithm and the genetic algorithm. For the ImprovedBPNN model author used channel state information for the prediction of spectrum rather than channel power and also from the Simulation results author concluded that the Spectrum predictive accuracy of Improved-Back-Propagation Neural Network is higher than the Conventional Back-Propagation Neural Network

\section{Different Techniques used for Cognitive Radio}

\section{Table 1. Different Techniques used for Cognitive Radio}

\begin{tabular}{|c|c|c|c|}
\hline AUTHOR & TITLE & YEAR & OBJECTIVE \\
\hline $\begin{array}{l}\text { Vamsi Krishna } \\
\text { Tumuluru, Ping Wang* } \\
\text { and Dusit Niyato }\end{array}$ & $\begin{array}{l}\text { A Neural Network } \\
\text { Based Spectrum } \\
\text { Prediction Scheme for } \\
\text { Cognitive Radio }\end{array}$ & 2010 & $\begin{array}{l}\text { Authors used the MLP algorithm } \\
\text { for spectrum prediction which } \\
\text { improves the spectrum utilization } \\
\text { and reduced the sensing energy }\end{array}$ \\
\hline $\begin{array}{l}\text { Anirudh Agarwal1, } \\
\text { Shivangi Dubey, } \\
\text { Mohd. Asif Khan1, } \\
\text { Ranjan Gangopadhyay } \\
\text { and Soumitra Debnat }\end{array}$ & $\begin{array}{l}\text { Learning Based } \\
\text { Primary User Activity } \\
\text { Prediction in Cognitive } \\
\text { Radio Networks for } \\
\text { Efficient Dynamic } \\
\text { Spectrum Access }\end{array}$ & 2016 IEEE & $\begin{array}{l}\text { To provide a longest idle } \\
\text { time of unused spectrum to the } \\
\text { unlicensed user by using } \\
\text { machine learning technique. } \\
\text { Four supervised machine } \\
\text { learning techniques (two from }\end{array}$ \\
\hline
\end{tabular}




\begin{tabular}{|c|c|c|c|}
\hline & & & ANN and two from SVM) \\
\hline $\begin{array}{l}\text { Pavithra Roy, Dr. } \\
\text { Muralidhar }\end{array}$ & $\begin{array}{lr}\text { Channel } & \text { State } \\
\text { Prediction in A } \\
\text { Cognitive Radio } \\
\text { Network Using Neural } \\
\text { Network Levenberg } \\
\text { Marquardt Algorithm }\end{array}$ & $\begin{array}{l}\text { Journal, } \\
2015\end{array}$ & $\begin{array}{l}\text { To predict the idle slots in the } \\
\text { channel which is based on the } \\
\text { past information and then allow } \\
\text { CR to select best slot for data } \\
\text { transmission. For idle slots } \\
\text { prediction, Neural Network } \\
\text { Levenberg-Marquardt (NNLM) } \\
\text { algorithm is used. }\end{array}$ \\
\hline $\begin{array}{l}\text { Rahul Singh and Sarita } \\
\text { Kansal }\end{array}$ & $\begin{array}{l}\text { Performance } \\
\text { Evaluation of Neural } \\
\text { Network based } \\
\text { Spectrum Sensing in } \\
\text { Cognitive Radio }\end{array}$ & $\begin{array}{l}2016, \\
\text { International } \\
\text { Conference }\end{array}$ & $\begin{array}{l}\text { The goal is to increase the } \\
\text { decision accuracy in the presence } \\
\text { of noise in the environment for } \\
\text { secondary user by using neural } \\
\text { network based spectrum sensing. } \\
\text { Neural network is an intelligent } \\
\text { or smart technique to predict the } \\
\text { unused spectrum }\end{array}$ \\
\hline $\begin{array}{l}\text { Vamsi Krishna } \\
\text { Tumuluru, Ping Wang* } \\
\text { and Dusit Niyato }\end{array}$ & $\begin{array}{l}\text { Channel status } \\
\text { prediction for } \\
\text { cognitive radio } \\
\text { network }\end{array}$ & IEEE, 2010 & $\begin{array}{l}\text { Two techniques Multilayer } \\
\text { Perceptron and Hidden Markov } \\
\text { Model for Spectrum prediction. } \\
\text { The advantage of channel } \\
\text { predictor is that these do not } \\
\text { require prior knowledge of the } \\
\text { channel. Compared the accuracy } \\
\text { of Multilayer Perceptron \& } \\
\text { Hidden Markov model }\end{array}$ \\
\hline $\begin{array}{l}\text { Rahul Singh and Sarita } \\
\text { Kansal }\end{array}$ & $\begin{array}{l}\text { Artificial neural } \\
\text { network based } \\
\text { spectrum Recognition } \\
\text { in cognitive radio }\end{array}$ & IEEE, 2016 & $\begin{array}{l}\text { The basic purpose is to increase } \\
\text { decision accuracy under the } \\
\text { various different noisy condition } \\
\text { and it have implemented by } \\
\text { using Multilayer Perceptron } \\
\text { Neural Network }\end{array}$ \\
\hline $\begin{array}{l}\text { Maciej Jolanta Mizera- } \\
\text { Pietraszko }\end{array}$ & $\begin{array}{l}\text { Contextual Neural- } \\
\text { Network Based } \\
\text { Spectrum Prediction } \\
\text { for Cognitive Radio }\end{array}$ & Conference, 2015 & $\begin{array}{l}\text { Contextual sigma-if neural } \\
\text { network is used to predict the } \\
\text { status of channel or spectrum } \\
\text { status for Cognitive Radio. From } \\
\text { the simulation results it is } \\
\text { concluded that the Contextual } \\
\text { Sigma-if algorithm is slightly } \\
\text { better than MLPN for prediction } \\
\text { and also it reduces the sensing } \\
\text { time for prediction. }\end{array}$ \\
\hline $\begin{array}{l}\text { Ojenge Winston, } \\
\text { Afullo Thomas and } \\
\text { William Okello } \\
\text { Odongo }\end{array}$ & $\begin{array}{l}\text { Comparing } \\
\text { Performance of MLP } \\
\text { and RBF Neural } \\
\text { Networks for TV Idle } \\
\text { Channel Prediction in } \\
\text { Cognitive Radio }\end{array}$ & Conference,2013 & $\begin{array}{l}\text { Compared the performance of } \\
\text { two most popular neural network } \\
\text { algorithms, Multilayer } \\
\text { Perceptron Neural Network and } \\
\text { Radial Basis Function Neural } \\
\text { Network, the mean square error } \\
\text { value of MLP is } 0.066666 \text { and } \\
\text { mean square error value of RBF } \\
\text { is } 0.0835026\end{array}$ \\
\hline
\end{tabular}




\begin{tabular}{|c|c|c|c|}
\hline $\begin{array}{l}\text { Xuezhi Tan, Haoqin } \\
\text { Huang, Lin Ma }\end{array}$ & $\begin{array}{l}\text { Frequency Allocation } \\
\text { with Artificial Neural } \\
\text { Networks in Cognitive } \\
\text { Radio System }\end{array}$ & IEEE,2013 & $\begin{array}{l}\text { In this paper author used the BP } \\
\mathrm{NN} \text { for the prediction of the } \\
\text { spectrum holes and from the } \\
\text { simulation results he concluded } \\
\text { that BP NN give the accurate } \\
\text { results for the complicated } \\
\text { frequency allocation }\end{array}$ \\
\hline $\begin{array}{l}\text { S.Pattanayak, P. } \\
\text { Venkateswaran R } \\
\text {.Nandi }\end{array}$ & $\begin{array}{l}\text { Artificial Neural } \\
\text { Networks for } \\
\text { Cognitive Radio }\end{array}$ & IEEE, 2012 & $\begin{array}{l}\text { Author used the combination of } \\
\text { Cognitive radio and ANN for the } \\
\text { prediction of spectrum holes and } \\
\text { then predicted spectrum is } \\
\text { assigned to CR user without } \\
\text { causing any interference and } \\
\text { which increases QoS }\end{array}$ \\
\hline $\begin{array}{l}\text { Sandhya Pattanayak } \\
\text {, R .Nandi }\end{array}$ & $\begin{array}{l}\text { Identification of } \\
\text { Spectrum Holes } \\
\text { using ANN Model for } \\
\text { Cognitive Radio } \\
\text { Applications }\end{array}$ & IEEE, 2013 & $\begin{array}{l}\text { In this paper author used ANN } \\
\text { model for the prediction of } \\
\text { channel status whether it is } \\
\text { occupied or not and also } \\
\text { designed three ANN models with } \\
\text { different hidden layers and } \\
\text { multiple neurons }\end{array}$ \\
\hline $\begin{array}{l}\text { Suya Bai, Xin Zhou, } \\
\text { Fanjiang Xu }\end{array}$ & $\begin{array}{l}\text { Spectrum Prediction } \\
\text { based on Improved- } \\
\text { Back- } \\
\text { Propagation Neural } \\
\text { Networks }\end{array}$ & 2015 & $\begin{array}{l}\text { Author used Improved-BP NN } \\
\text { for the prediction of spectrum } \\
\text { holes which overcomes the } \\
\text { weaknesses of Conventional BP } \\
\text { NN }\end{array}$ \\
\hline
\end{tabular}

\section{Conclusion}

Using artificial neural network we can achieve our goal of spectrum prediction, which is vital for cognitive engine. Among various machine learning techniques used, ANN stands out to be the most useful technique as it doesn't require much priori knowledge of the system to make decisions. But implementing ANN adds complexity in the system. From above discussion it can be concluded that certain modifications in the ANN system makes it more accurate. Perceptron neural network is more accurate than Elman or Feed Forward neural network. Its accuracy is also higher than that of RBF (Radial Bias Function) or other popular machine learning techniques like HMM. While, Neural Network Levenberg-Marquardt algorithm performs even better than perceptron neural network.

\section{References}

[1] S. Haykin, "Cognitive radio: brain-empowered wireless communications", IEEE J. Sel. Areas Commun., vol. 23, (2005), pp. 201- 220.

[2] J. Mitola III, "Cognitive Radio: An Integrated Agent Architecture for Software Defined Radio", Ph.D. Dissertation Royal Instt.Tech., Sweden, (2000).

[3] Federal Communications Commission, ET Docket No. 03-108, (2005).

[4] J. Neel, "Synthetic symmetry in cognitive radio networks", in Proc. Forum Tech. Conf. Product Expo. SDR, Denver, Co, (2007).

[5] M. McHenry, "NSF Spectrum Occupancy Measurements Project Summary", [Online]. Available: http://www.sharedspectrum.com/?section=nsf_measurements, (2005).

[6] D. Niyato and E. Hossain, "Spectrum trading in cognitive radio networks: A market-equilibrium-based approach", IEEE Wireless Commun., vol. 15, no. 6, (2008), pp. 71-80.

[7] P. Greenis, "Smart communications for smart grids", in Proc. Nanotech Conf. Expo, Houston, TX, (2009). 
[8] W. Lane, "Topic 9: Cognitive Radio Potential for Public Safety", [Online]. Available: http://www.fcc.gov/pshs/techtopics/techtopic9.html

[9] Ubiquisys, Ubiquisys and Percello, "Unveil Next Generation Femtocell Platform”, Jun. 22, 2009. [Online]. Available: http://www.ubiquisys.com/, ub3b/pressreleases.php?id=115 1590 IEEE Transactions On Vehicular Technology, vol. 59, no. 4, (2010).

[10] C. Lu, F. H. P. Fitzek and P. C. F. Eggers, "A cooperative scheme enabling spatial reuse in wireless networks", Wireless Commun. Mag., vol. 15, no. 6, (2007), pp. 457-471.

[11] S. Haykin, "Neural Networks: A Comprehensive Foundation", NJ: Prentice-Hall, (1999).

[12] S. Haykin, "Neural Networks: A Comprehensive Foundation", Upper Saddle River, NJ: Prentice-Hall, (1999).

[13] A. Fehske, J. Gaeddert and J. H. Reed, "A new approach to signal classification using spectral correlation and neural networks," in Proc. 1st IEEE Int. Symp. New Frontiers DySPAN, Baltimore, MD, (2005), pp. 144-150.

[14] X.-L. Zhu, Y.-A. Liu, W.-W. Weng and D.-M. Yuan, "Channel sensing algorithm based on neural networks for cognitive wireless mesh networks", in Proc. 4th Int. Conf. WiCOM, Dalian, China, (2008), pp. $1-4$.

[15] A. F. Cattoni, M. Ottonello, M. Raffetto and C. S. Regazzoni, "Neural networks mode classification based on frequency distribution features", in Proc. 2nd Int. Conf. CrownCom, Orlando, FL, (2007), pp. 251-257.

[16] J. H. Reed, "Development of a Cognitive Engine and Analysis of WRAN Cognitive Radio Algorithms—Phase I", Wireless @ Virginia Tech, Virginia Polytech. Inst. State Univ., Blacksburg, VA, (2005).

[17] Z. Zhang and X. Xie, "Intelligent cognitive radio: Research on learning and evaluation of CR based on neural network", in Proc. ITI 5th ICICT, Dhaka, Bangladesh, (2007), pp. 33-37.

[18] P. Kolodzy, "Next generation communications: Kickoff meeting", Proc. DARPA, (2001).

[19] T. Costlow, "Cognitive radios will adapt to users", IEEE Intell. Syst., vol. 18, no. 3, (2003), p. 7.

[20] S. K. Jayaweera and C. G. Christodoulou, "Radiobots: Architecture, algorithms and realtime reconfigurable antenna designs for autonomous, self-learning future cognitive radios", University of New Mexico, Technical Report EECE-TR-11-0001, [Online]. Available: http://repository.unm.edu/handle/1928/12306, (2011).

[21] S. Haykin, "Cognitive radio: brain-empowered wireless communications", IEEE J. Sel. Areas Commun., vol. 23, no. 2, (2005), pp. 201-220.

[22] X. Dong, Y. Li, C. Wu and Y. Cai, "A learner based on neural network for cognitive radio", Comm. Tech. 12th IEEE International Conference on ICCT, (2010), pp.893-896.

[23] A. El-Saleh, M. Ismail, M. Ali and J. Ng, "Development of a cognitive radio decision engine using multi-objective hybrid genetic algorithm", in IEEE 9th Malaysia International Conference on Communications (MICC 2009), (2009), pp. $343-347$.

[24] H. Volos and R. Buehrer, "Cognitive engine design for link adaptation: An application to multi-antenna systems”, IEEE Trans. Wireless Comm., vol. 9, no. 9, (2010), pp. $2902-2913$.

[25] J. Mitola, "Cognitive radio: An integrated agent architecture for software defined radio", Ph.D. dissertation, Royal Institute of Technology (KTH), Stockholm, Sweden, (2000).

[26] J. Mitola, "Cognitive radio architecture evolution”, Proc. IEEE, vol. 97, no. 4, (2009), pp. 626 -641.

[27] S. Jayaweera, Y. Li, M. Bkassiny, C. Christodoulou and K. Avery, "Radiobots: The autonomous, selflearning future cognitive radios", in International Symposium on Intelligent Signal Processing and Communications Systems (ISPACS '11), Chiangmai, Thailand, (2011), pp. 1 -5.

[28] C. Clancy, "Applications of machine, learning to cognitive radio networks", IEEE Wireless Commun., vol. 14 , no. 4 , (2007).

[29] A. Amraoui, B. Benmammar, F. Krief and F.T. Bendimerad, "Intelligent wireless communication system using cognitive radio", IJDPS Int. J. Distrib. Parallel System, vol 3, no. 2, (2012), pp. 91-104.

[30] "ET docket no 03-322 notice of proposed rulemaking and order", Tech. Rep., (2003).

[31] N. Devroye, M. Vu and V. Tarokh, "Cognitive radio networks", IEEE Signal Processing Mag., vol. 25, (2008), pp. 12-23.

[32] A. Goldsmith, S. A. Jafar, I. Maric and S. Srinivasa, "Breaking spectrum gridlock with cogntive radios: An information theoretic perspective", Proc. IEEE, vol. 97, no. 5, (2009), pp. 894-914.

[33] M. Bkassiny, S. K. Jayaweera and K. A. Avery, "Distributed reinforcement learning based MAC protocols for autonomous cognitive secondary users", in 20th Annual Wireless and Optical Communications Conference (WOCC '11), Newark, NJ, (2011), pp. 1 -6.

[34] "Blind cyclostationary feature detection based spectrum sensing for autonomous self-learning cognitive radios", in IEEE International Conference on Communications (ICC '12), Ottawa, Canada, (2012).

[35] V. K. Tumuluru, P. Wang and D. Niyato, "A Neural Network Based Spectrum Prediction Scheme for Cognitive Radio", IEEE ICC, (2010).

[36] A. Agarwal1, S. Dubey, M.A. Khan, R. Gangopadhyay and S. Debnat, "Learning Based Primary User Activity Prediction in Cognitive Radio Networks for Efficient Dynamic Spectrum Access". 
[37] P. Roy and Muralidhar, "Channel State Prediction in A Cognitive Radio Network Using Neural Network Levenberg Marquardt Algorithm", in International Journal of Wireless Communications and Networking Technologies, vol. 4, no.2, (2015).

[38] R. Singh and S. Kansal, "Performance Evaluation of Neural Network based Spectrum Sensing in Cognitive Radio", 2016 International Conference on Internet of Things and Applications (IOTA) Maharashtra Institute of Technology, Pune, India, (2016).

[39] R. Singh and S. Kansal, "Artificial neural network based spectrum Recognition in cognitive radio", in Conference on Electrical, Electronics and Computer Science, IEEE Students, (2016).

[40] M. Jolanta and Mizera-Pietraszko, "Contextual Neural-Network Based Spectrum Prediction for Cognitive Radio".

[41] O. Winston, A. Thomas and W. Okello Odongo, "Comparing Performance of MLP and RBF Neural Networks for TV Idle Channel Prediction in Cognitive Radio", Pan African International Conference on Information Science, Computing and Telecommunications, (2013).

[42] X. Tan, H. Huang and L. Ma "Frequency Allocation with Artificial Neural Networks in Cognitive Radio System", in IEEE 2013 Tencon - Spring.

[43] S. Pattanayak, P. Venkateswaran and R .Nandi, "Artificial Neural Networks for Cognitive Radio", in 2012 IEEE.

[44] S. Pattanayak and R .Nandi, "Identification of Spectrum Holes using ANN Model for Cognitive Radio Applications", in EuroCon 2013, Zagreb, Croatia, (2013).

[45] S. Bai, X. Zhou and F. Xu, "Spectrum Prediction based on Improved-Back-Propagation Neural Networks", in 2015 11th International Conference on Natural Computation (ICNC).

[46] A. Bagwari and G.S. Tomar, "Cooperative Spectrum Sensing with Adaptive Double-Threshold Based Energy Detector in Cognitive Radio Networks", Springers International Journal of wireless personal Communication, vol. 73, no.3, (2013), pp 1005-19. 